\title{
Foreign Body Removal
}

National Cancer Institute

\section{Source}

National Cancer Institute. Foreign Body Removal. NCI Thesaurus. Code C50821.

The extraction of an object not native to the human body. 